\title{
Revenue Management in Make-To-Order Manufacturing: Case Study of Capacity Control at ThyssenKrupp VDM
}

\author{
André Hintsches, Institute of Automotive Management and Industrial Production, Technische Universität Braunschweig, \\ E-Mail: a.hintsches@tu-braunschweig.de \\ Thomas S. Spengler, Institute of Automotive Management and Industrial Production, Technische Universität Braunschweig, \\ E-Mail: t.spengler@tu-braunschweig.de \\ Thomas Volling, Institute of Automotive Management and Industrial Production, Technische Universität Braunschweig, \\ E-Mail: t.volling@tu-braunschweig.de \\ Kai Wittek, Institute of Automotive Management and Industrial Production, Technische Universität Braunschweig, \\ E-Mail:k.wittek@tu-braunschweig.de \\ Gerald Priegnitz, ThyssenKrupp VDM, Werdohl,E-Mail: gerald.priegnitz@thyssenkrupp.com
}

\begin{abstract}
While revenue management (RM) is traditionally considered a tool of service operations, $R M$ shows considerable potential for application in manufacturing operations. The typical challenges in make-to-order manufacturing are fixed manufacturing capacities and a great variety in offered products, going along with pronounced fluctuations in demand and profitability. Since Harris and Pinder in the mid-9os, numerous papers have furthered the understanding of RM theory in this environment. Nevertheless, results to be expected from applying the developed methods to a practical industry setting have yet to be reported. To this end, this paper investigates a possible application of RM at ThyssenKrupp VDM, leading to considerable improvements in several areas.
\end{abstract}

Keywords: linear programming applications, make-to-order, manufacturing, steel industry, capacity control

Manuscript received December 1, 2009, accepted by Karl Inderfurth (Operations and Information Systems) April 21, 2010.

\section{$1 \quad$ Introduction and Motivation}

After stagnating for decades, the demand for steel products has grown since the mid-9os. A similar increase in demand took place for the non-ferrous alloys. In particular, the high-quality product segments were characterized by supply deficits (ThyssenKrupp 2006). Figure 1 reflects the developments of the worldwide manufactured quantities of highquality products based on nickel alloys and the demand for primary nickel. Both time series exhibit a positive trend over the last 15 years. With a consumption of 240 kilotons, the market reached its hitherto peak in 2006.

If the demand exceeds manufacturing capacity on a regular basis, companies are confronted with the challenge to optimize order acceptance (Spengler, Rehkopf, and Volling 2007). The objective is to maximize the overall profit by adequately selecting the best orders. Thus, companies are confronted with the decision to dynamically control the inflow of orders. This constitutes a classical environment for employing the techniques of RM, capacity control in particular. By quantitatively assessing the opportunity costs of an order, RM provides support for order acceptance decisions.

The airline industry is the most familiar application of RM and its techniques have been effectively applied to many areas of the service industry. Many common characteristics between order-driven manufacturing and traditional RM industries make manufacturing industries in general, and make-toorder steel manufacturing in particular, promising environments for the application of RM. Since research in this area is still in its infancy (Chiang, Chen, and $\mathrm{Xu}$ 2007), this paper's objective is to contribute to the understanding by sharing expe- 
riences in terms of the potential, current success, and difficulties when investigating a planned implementation of RM at a worldwide leading manufacturer of high-performance alloys, operating a make-to-order (m-t-o) production.

\section{Figure 1: Development of demand for primary nickel and products on the basis of nickel alloys}

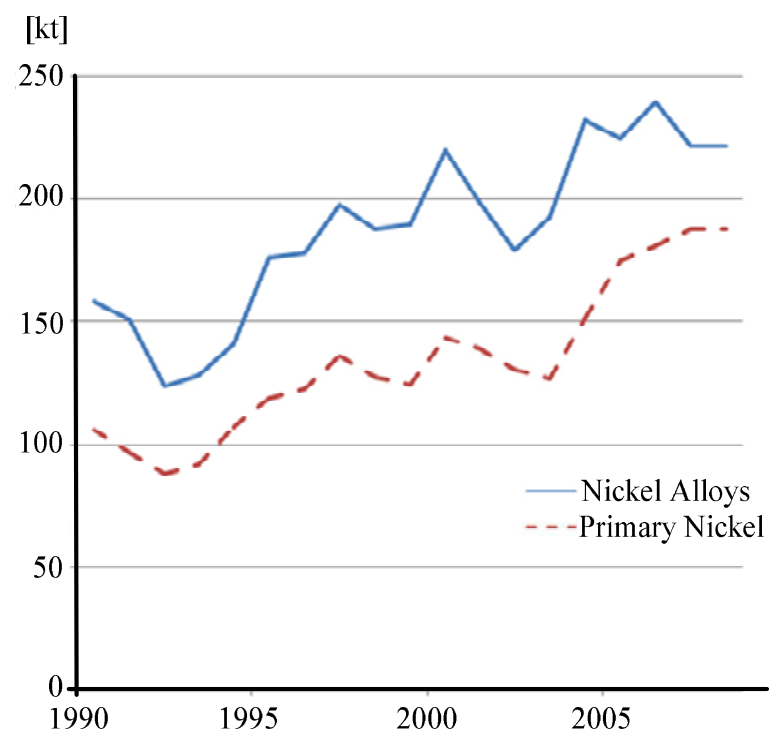

\section{$2 \quad$ Make-to-Order Steel Manufacturing}

ThyssenKrupp is one of the world's largest technology groups. Worldwide, more than 190,000 employees work in the group's main areas of steel, capital goods and services, realizing sales of more than 53 billion EUR in the 2007/2008 fiscal year.
The ThyssenKrupp Stainless segment is the world's market leader in flat-rolled stainless products and holds leading positions in high-performance material markets. In the ThyssenKrupp Stainless segment eight business units in stainless-steel products are concentrated, two of which serve the market for high-performance alloys: ThyssenKrupp Titanium and ThyssenKrupp VDM.

ThyssenKrupp VDM is a leading international supplier of high-performance nickel alloys, cobalt alloys, and special stainless steels. The company supplies these products in the form of sheet, strip, bar, and wire to customers mainly in the energy, oil, gas, plant construction, aerospace, and electronics sectors. Products of high-performance alloys are used whenever extreme conditions are faced, for instance in fuel cells, turbine blades or high-precision molds. With about 1,800 employees, ThyssenKrupp VDM accounts for shipments of 36,100 metric tons, and sales of 1,177 million EUR in the 2007/2008 fiscal year.

The company's manufacturing streams of its four product segments are depicted in Figure 2. Starting with the melting and casting of the raw material in the common upstream melting plant, the material is distributed in the form of ingots into different manufacturing streams. Thus, the production process can be described as a combination of process and discrete production.

Within the above-described production process, the capacities of the finishing sections are the limiting factors. In particular, the sheet finishing section experiences a demand exceeding the capacity on a regular basis. For that reason, this paper will focus on the sheet finishing section.

In this context, a product is defined as a specific set

Figure 2: ThyssenKrupp VDM's manufacturing streams

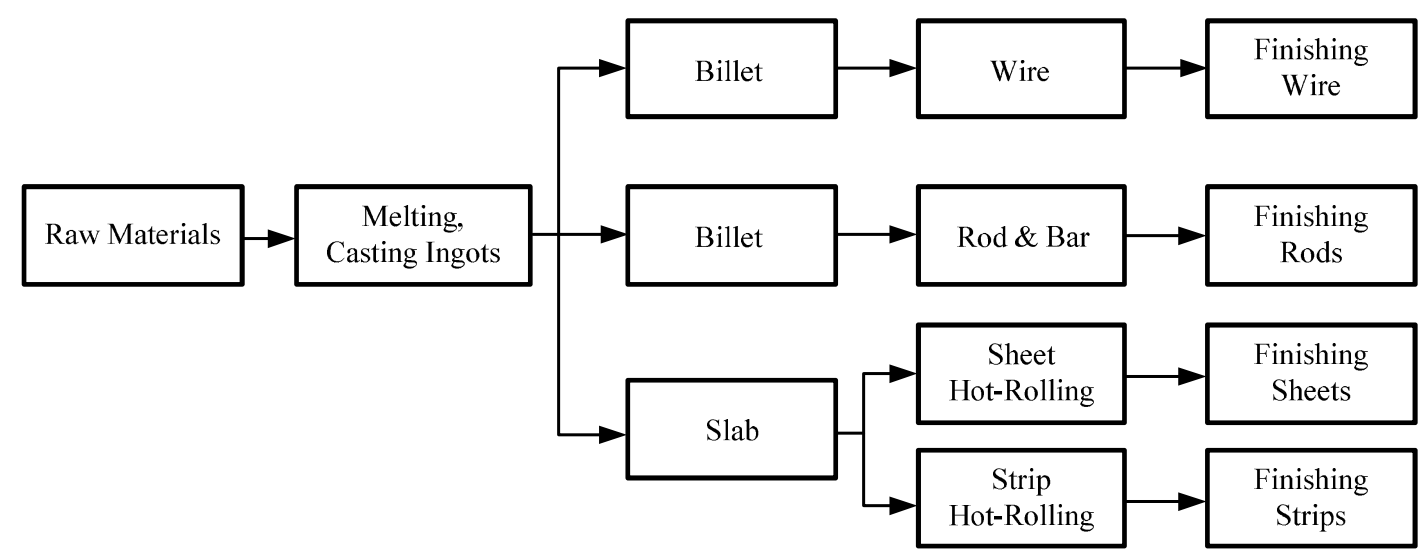


of specifications ordered by the customer, including type of alloy, type of forming, quality norms, and geometric measurements.

Sheet finishing begins with annealing, a heat treatment in which the recrystallization is conducted. The duration of the annealing process depends on the type of alloy and the order-specific thickness of the sheet. Afterwards, the sheets are blasted to prize the layer of scales and leveled in order to assure quality in further processing. In addition, by leveling and blasting the sheet, the efficiency of the subsequent pickling is increased. The descaled sheet is then taken through the spray pickling to achieve an oxide-free surface. Subsequently, the sheets are washed and dried. Customer orders with a thin thickness are cold-rolled. This cyclical production path (Figure 3) is to be passed through several times depending on the alloy and customer specifications. If these customer specifications state a certain treatment of the surface by the dry or wet grinding production units, the sheet is led into a second cyclical production path including the grinding units. The duration and number of utilizations of the grinding capacity depend on the type of alloy and the geometric measurements of the customer order. After being cut into the ordered measurements, the sheet is passed to quality inspection and eventually to shipping.

Even if only the type of alloy is considered, ThyssenKrupp VDM offers a variety of more than 50 different alloys, which leads to additional complexity in (i) finding a good policy for material stock keeping and (ii) in the order flow and the resulting capacity utilization.

Figure 4 illustrates the production routing of historic orders of two fiscal years, revealing the intense utilization of the first three production units and the optional utilization of the dry grinding. Out of 7,709 produced orders the vast majority requires some amount of capacity at the annealing, blasting and leveling processes.

The rest of the displayed production units are not frequented with as many orders as the above production units, which is due to the multiple options in production routing as depicted in Figure 3. This also explains the decrease in numbers of orders requiring capacity and the increase in possible production routes that include the production units spray pickling, cold-rolling, and dry grinding processes. Obviously, Figure 4 does not give infor- mation about the capacity load, but serves only to illustrate the complexity of production routing. Depending on the specifications of the customer order, a resource might be occupied several times during the production process. For instance, whereas a hot-rolled sheet usually occupies the annealing only once, a cold-rolled product occupies the annealing, blasting, and leveling several times (typically 2 to 4 times). Determinants are the ordered alloy and the thickness of the sheet.

\section{Figure 3: Production network in the sheet finishing section}

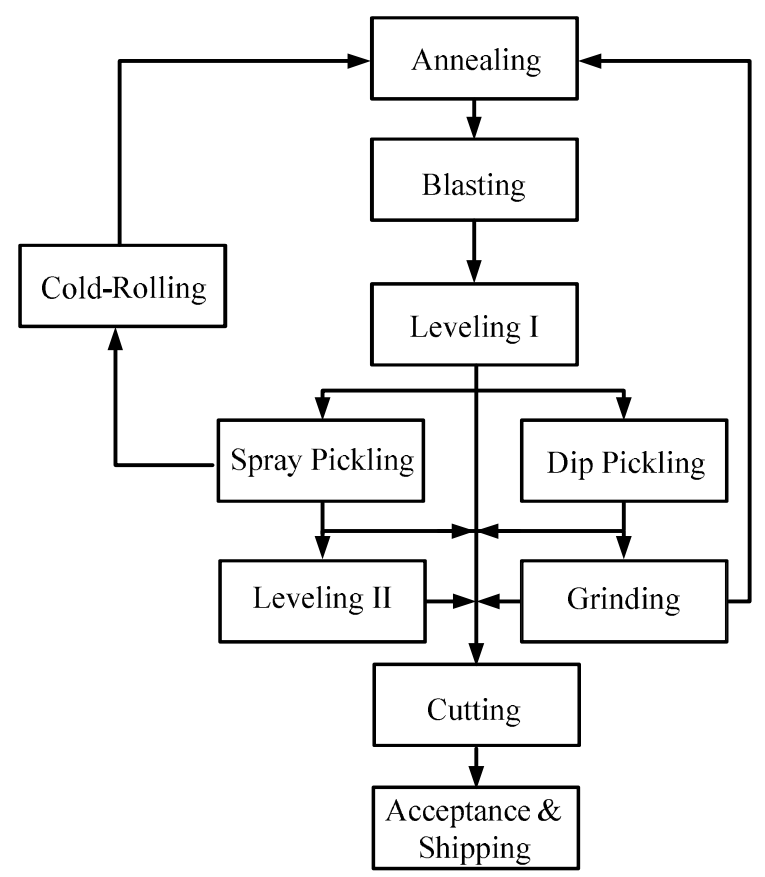

In addition to the order-specific production routing, the capacity requirements on a particular resource fluctuate heavily in relation to the ordered alloy and geometric specifications, i.e. length, width, and thickness. Interestingly, the capacity consumed on each production unit depends on different factors for each resource. For instance, the type of alloy and the sheet's thickness influence the capacity consumption at the annealing, resulting in a range of 0.02 to 3.57 hours around a mean value of 0.47 hours. On the other hand, the capacity consumed on the grinding machine constitutes for some products up to 19.46 hours with a mean value of 0.47 hours depending on alloy and square footage of the order. Combined with the findings of Figure 4, this results in high fluctuations of capacity loads as will be de- 
scribed in detail in section 5 . As a consequence, the short-term bottlenecks in this production network depend on the accepted orders and switch in each demand scenario.

For a complex production environment as the one described above, different approaches to cope with the complexity are discussed in literature. Dutta and Fourer (2001) provide an overview of typical planning problems, whereas Denton, Gupta, and Jawahir (2003) discuss approaches to handle the increasing product variety. A well-established approach to obtain a consistent production plan is the hierarchical production plan approach discussed in the steel industry context by Neureuther, Polak, and Sanders (2004), Lin and Moodie (1989), or Mohanty and Singh (1992). Examples of the practical application of planning models are provided by Tang and Liu (2007) and Tang, Liu, Rong, and Yang (2000).

Starting in the mid-9o's, initial works of Balakrishnan, Sridharan, and Patterson (1996), Harris and Pinder (1995) and Patterson, Balakrishnan, and Sridharan (1997) investigate the application of RM methods to manufacturing environments in general. Models of capacity control in m-t-o environments, specifically, are later presented by Barut and Sridharan (2005), Defregger and Kuhn (2007), Gallien, Le Tallec, and Schoenmeyr (2004), Gupta and Wang (2004) and Jalora (2006), all considering the sequential order acceptance for multiple offered products with exogenous delivery dates with respect to expected demand. Spengler, Rehkopf, and Volling (2007) extend the above list by additionally providing a detailed description of an observed production structure.

As mentioned above, short-term bottlenecks in the production network depend on the accepted orders and switch in each demand scenario. This constitutes a typical problem in m-t-o manufacturing, potentially causing tremendous inefficiencies in the interaction of order acceptance and production. Failure to consider the order's capacity consumption and resulting effects on the bottlenecks in the production stream may lead to losses in capacity and inefficient order acceptance decisions. In similar settings in the service industry, RM has significantly contributed towards improved order acceptance decisions (Cross 1997; Metters, Queenan, Ferguson, Harrison, Higbie, Ward, Barfield, Farley, Kuyumcu, and Duggasani 2008; Geraghty and Johnson 1997). Hence, implementing RM in the above-described setting promises great potential which will be further explained with details from practice in section 4.

\section{The Potential of Revenue Management in Make-to- Order Steel Manufacturing}

Most companies with m-t-o production possess characteristics that enable and motivate the usage of RM instruments. One of the common characteristics of companies in traditional RM applications is the rigidity of available capacity (Kimes 1989). Although capacity can be considered as flexible in the long term, increasing the capacity substantially in the short term is not possible. At ThyssenKrupp VDM the capacity of the majority of production units can only be expanded with substantial capital infusion, time lag, and downtime. Therefore, adapting available capacity to short-term fluctuations of demand is not practical (Harris and Pinder 1995).

Figure 4: Order flow of two fiscal years (numbers modified due to data confidentiality)

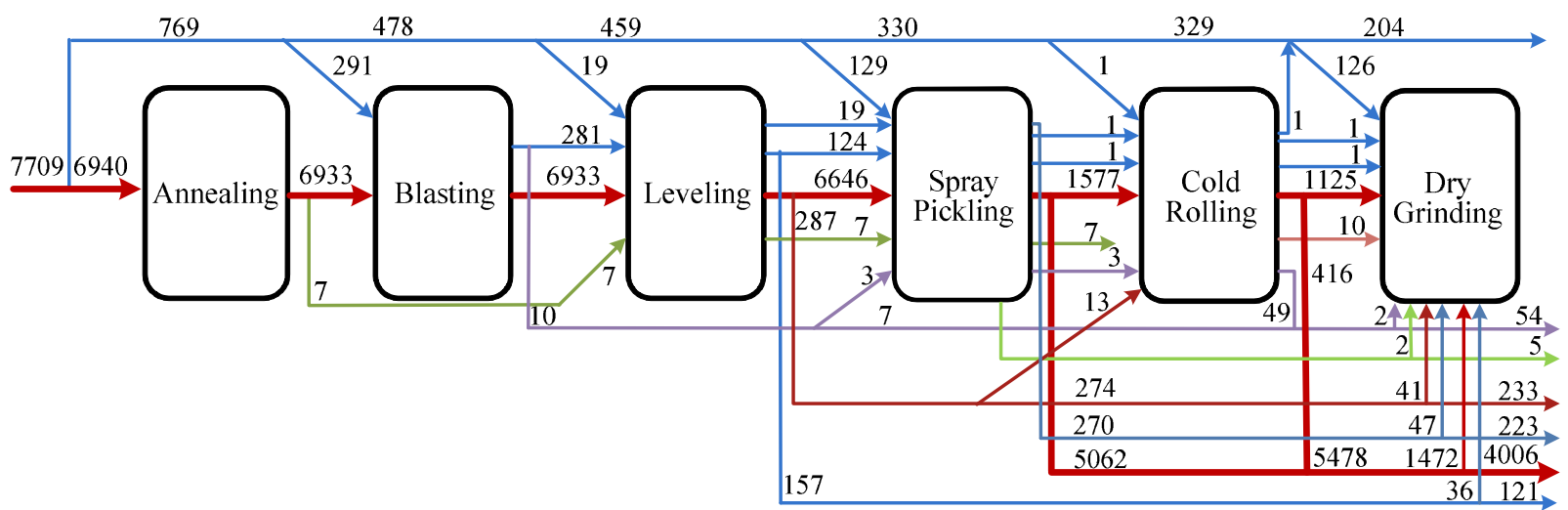


Further, Barut and Sridharan (2005) observe that quickly adding capacity could lead to a glut and seriously jeopardize the health of a company in the long term. The requirement of a capacity shortage is interconnected with fixed capacity. With unconstrained capacity, demand will never exceed capacity and the decision of accepting an order can simply be made by comparing the marginal profit with the marginal costs of an order (Kniker and Burman 2001). To generate this kind of decision, a RM system is not necessary.

In addition, for RM to be most effective, the production capacity in m-t-o steel manufacturing should be considered as perishable inventory (Kimes 1989). The common perception is that manufacturers do not face the problem of perishability. However, a company employing $\mathrm{m}$-t-o production relies on the knowledge of the relevant specifications of quality, quantity, and delivery date from the customer before production can begin. This knowledge therefore serves as the so-called external factor, which is a production factor required for the production of goods and services which cannot be controlled by the company. In the context of m-t-o manufacturing, it is not the product itself that has to perish, only the capacity to produce it (Swann 1999).

In order to apply RM in the order acceptance process, a company must have the ability to reject customer requests or to vary prices driven by its efforts to maximize the overall contribution margin. Obviously, decision-making requires an economical, legal and moral independency. In the case of ThyssenKrupp VDM this independency is very pronounced. On the one hand, this is due to a large amount of different customers, each of them with a limited economical impact to the overall results (ThyssenKrupp VDM's database consists of several thousand customers). On the other hand, the majority of ThyssenKrupp VDM's production capacity is not bound by long-term contracts and thus, is available for short-term project business giving the company an additional degree of freedom in the selection of orders.

Finally, for RM to be effective, it must be supported throughout the corporate culture and management of the company. At ThyssenKrupp VDM the introduction of RM was initiated and is supported by the company's top management, motivated by inefficient order acceptance decisions during times of excess demand and promising results of RM in similar settings (Spengler, Rehkopf, and Volling 2007).

Nevertheless, there are several characteristics distinguishing $\mathrm{RM}$ at a steel manufacturing facility from its counterparts in service industries. For instance, Gallien, Le Tallec, and Schoenmeyr (2004) point out that the production capacity in manufacturing settings is allocated over an infinite horizon, as opposed to the finite seat allocation period ending with a flight's departure. Further, it is possible to start production at any time during the day, whereas seats on a plane can only be sold for a specific departure time constrained by a reserved slot for takeoff. Most manufacturers are free to shift their production activities in time, as long as the end-delivery date is met. In manufacturing it is not a prespecified production time that is sold, but rather the certainty that an appointed activity will be performed somewhere within a specified period of time (Kniker and Burman 2001). This characteristic does not contradict the above-mentioned requirement of perishability. Despite the at-first-glance suspected additional degree of freedom, most customer orders are quoted for the soonest possible delivery date, which heavily relies on the upstream melting and casting routine. In addition, long lead times in production and high material costs further restrict the suspected additional degree of freedom making the available production capacity a perishable resource. Also, as a characteristic of the m-t-o production, significant variable costs need to be considered, influencing the profitability of order acceptance. Since ThyssenKrupp VDM offers Nickel alloys, material costs take up a large percentage of the final product price quoted to the customer. In contrast to the homogeneous capacity consumption faced by the airlines (one customer requires one seat on the airplane), the capacity consumption and number of required production units in a m-t-o environment differ from each other. Therefore, the assumption that an increase in revenues automatically results in an increase in profits is not necessarily true. The objective of capacity control in the service industry to maximize revenues needs to be replaced by the maximization of the overall contribution margin.

One special characteristic of the order acceptance process of companies selling highly customized products is the iterative process of price negotiations, which is explained in detail in the following section. Defregger and Kuhn (2007) show that in 
order to effectively apply RM, a company needs to be able to segment the customers into classes of higher and lower price sensitivity. Due to the price negotiations between sales personnel and the customers, not only the products are customized, but to a certain extent, the price as well. It can therefore be assumed that the sales personnel are able to skim the customer's willingness to pay.

In summary, despite the differences of service and manufacturing industries, the requirements for the effective implementation of RM techniques are met at ThyssenKrupp VDM. Nevertheless, to comprehend the decision support provided by RM techniques, a detailed look at the order acceptance process is necessary.

\section{The Order Acceptance Process and Order Characteristics at ThyssenKrupp VDM}

The process of order acceptance in m-t-o companies differs from service industries. Usually, the customer approaches ThyssenKrupp VDM either through one of the worldwide subsidiaries or directly contacts the sales department in the headquarters (Figure 5). The sales agent uses the customer's information about the desired alloy, specification and quantity to perform both the ATP and CTP checks. Hereby, the Available to Promise (ATP) identifies already-existing inventory that is available to fulfill the request. Due to the great product variability, no significant inventory of pre-products exists, increasing the importance of the Capable to Promise (CTP) check in m-t-o manufacturing. The CTP check compares the request's specific capacity consumption with the available production capacity and thus, verifies if enough production capacity and material is available to fulfill the request, resulting in the soonest possible date of delivery. Afterwards, the profitability check results in a comparison of the lowest quotation price based on production costs and the customer's willingness to pay. The request is accepted and the available production resources updated if the customer's willingness to pay exceeds the lowest quotation price. If the customer's willingness to pay is exceeded by the lowest quotation price, the request is marked as not profitable. This information is used in further negotiations with the customer, resulting either in the customer's acceptance of a price exceeding the lowest quotation price, the change of specifications ("new request") or the rejection of the request. At this stage, the subsidiaries do not necessarily have to be included. The use of the terms "acceptance" and "rejection" in this context might suggest a situation where ThyssenKrupp VDM's only decision is to either accept or reject the customer's terms. In practice, sales agents often take a more active role in the actual interaction with the customer, which is frequently a process of iterative negotiation.

The sales personnel at ThyssenKrupp VDM face a difficult task when classifying an incoming customer

Figure 5: Interaction of sales agent and customer during order acceptance process

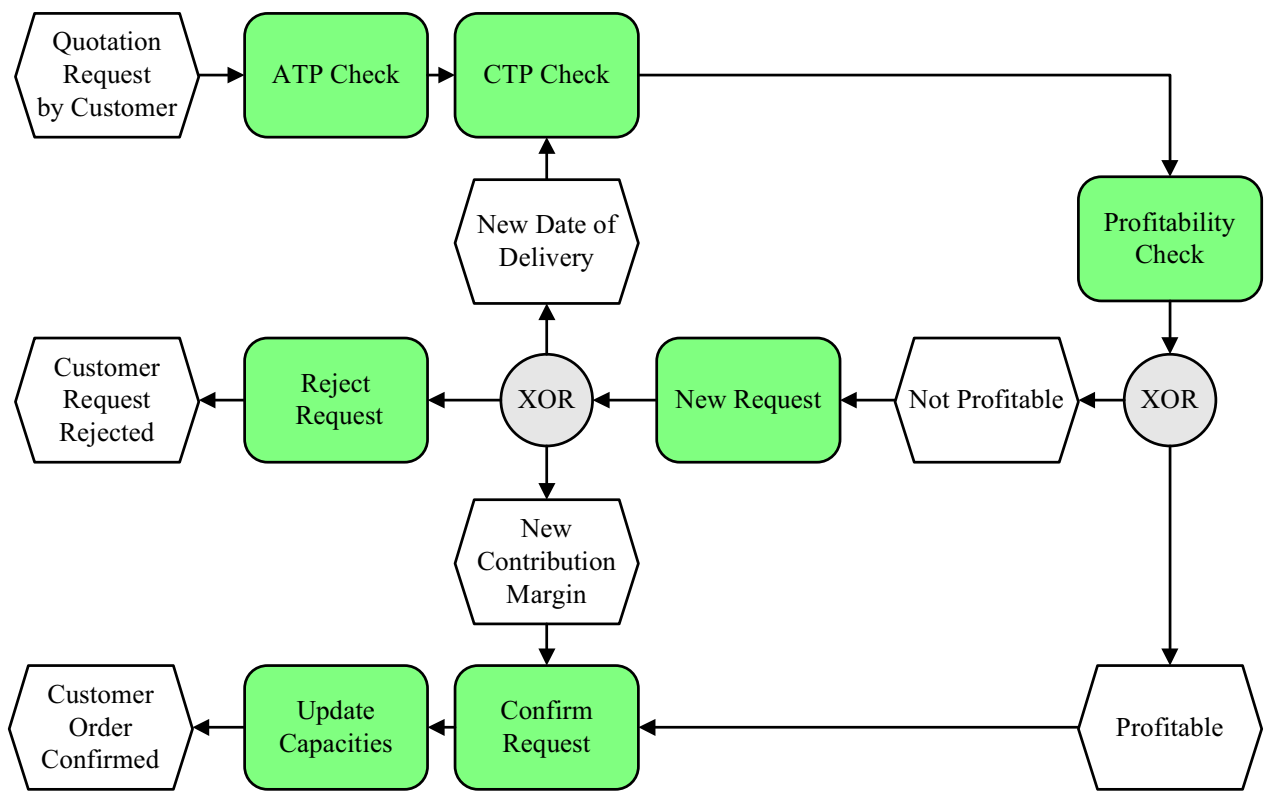


request as profitable to accept or not. Figure 6 depicts the high fluctuation in contribution margin per $\mathrm{kg}$ of an actual sequence of incoming customer orders observed in one specific month. One can observe the high variance in specific contribution margin of the orders, fluctuating with a coefficient of variation of 0.495 . No clear pattern of profitability in this sequence of orders can be observed. Since it is the policy of ThyssenKrupp VDM that every request for a quotation is answered within 24 hours, it is not possible for the sales agents to delay a response for tactical reasons.

\section{Figure 6: High variance in specific contribution margin of customer orders within one month}

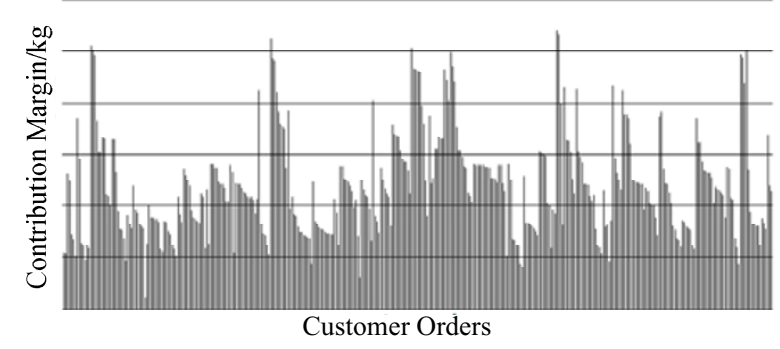

This observed high variance in contribution margin is mainly due to the large variety of products offered by ThyssenKrupp VDM and the price negotiations. The large offered variety of products results in a broad spectrum of contribution margins. Each alloy achieves different average contribution margins. As a rule of thumb, the highly customized alloys achieve higher average contribution margins than the volume-intense alloys. For instance, with a total amount of 51 offered alloys, only 15 alloys make up about $80 \%$ of the ordered quantity. Whereas the 28 alloys representing only $5 \%$ of the total ordered quantity result in a contribution margin which is $300 \%$ higher than the contribution margin of the volume-intense alloys.

In addition to the different average contribution margins of the alloys, the achieved contribution margin differs for each order depending on the technical specifications (e.g., industry specific quality standard) and the price negotiations.

Nevertheless, the volume is not a good indication of the resulting capacity consumption of an order. Even if the width, the length, and the type of alloy of two orders are identical, the capacity consumption of each order is heavily influenced by the specified thickness. For instance, a sheet with a thickness of less than $3 \mathrm{~mm}$ needs to be cold-rolled and, thus, occupies the production units multiple times as mentioned previously in the description of the production process. Obviously, a very thin, cold-rolled sheet is lighter than a thicker sheet, but requires more capacity during the production.

Evaluating an order's profitability regarding contribution margin per kg, while failing to consider its capacity consumption, leads to erroneous information during times of excess demand. To provide an example of the effect of considering the capacity consumption of an order when deciding about its profitability, Figure 7 on the left shows the same orders as Figure 6. Now however, the orders are sorted according to their contribution margin per $\mathrm{kg}$ relative to the average realized contribution margin of that particular month. On the right side of Figure 7 , the orders are sorted in the same manner as on the left side, but this time depicted according to the contribution margin per hour of annealing capacity consumed.

Interestingly, an order that is classified better than average with respect to contribution margin per $\mathrm{kg}$ might not necessarily be better than average with

Figure 7: Customer orders depicted by EUR/kg and EUR/h
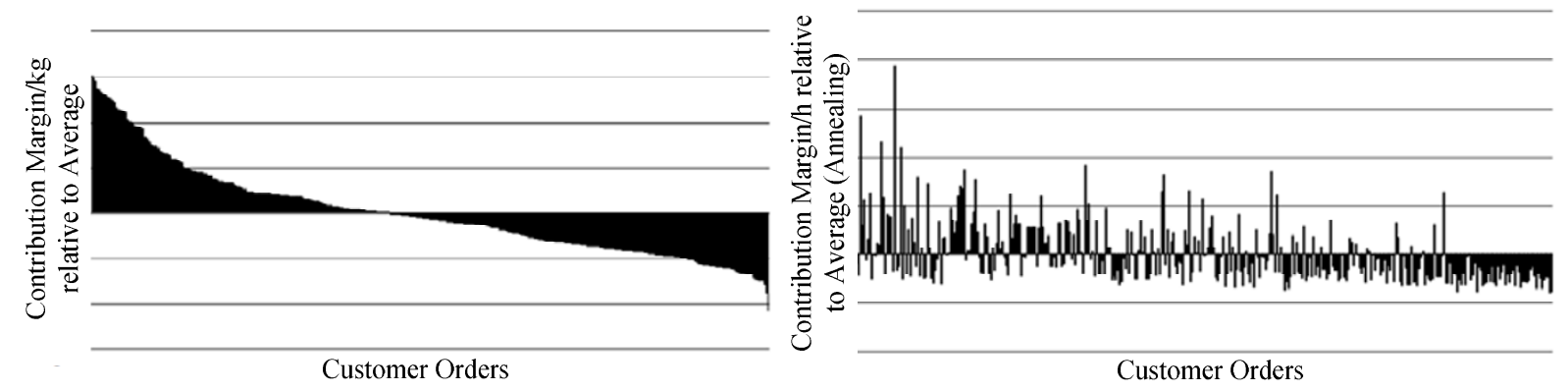
regard to contribution margin per annealing capacity consumed and vice versa. If annealing was the only bottleneck in the production network, evaluating the order regarding contribution margin per $\mathrm{kg}$ would have resulted in misleading information, as the correlation coefficient (Pearson) of EUR $/ \mathrm{kg}$ and $\mathrm{EUR} / \mathrm{h}$ in this specific case is only 0.459 (the values for the other production units are even lower).

Even if the capacity consumption is taken into account when evaluating customer orders, in an m-t-o environment the bottleneck typically is not static. It switches depending on the specifications of other incoming customer orders. Therefore, in m-t-o steel manufacturing the bottlenecks cannot be defined ex-ante, causing a need for additional information and coordination between sales and production to master the complexity of the order acceptance decision.

The negative results of not incorporating the resulting capacity consumption and the forecast of incoming requests into the order acceptance process can be quantified using an ex-post analysis. The production capacity of a certain period was systematically overloaded, meaning that more customer requests were coming in than production capacity was available. Hereby, the arrival of unconstrained demand was simulated using historic order information. Although no information about the lost orders was recorded at the time of the project, using historical actually produced orders to overload the capacity is eligible since all orders have the same probability of occurrence.

Requests were accepted or declined according to current practice. As such, a first-come-first-served policy (FCFS) was applied, accepting all requests in the sequence of their arrival if (i) the request has a positive contribution margin and (ii) enough capacity is available to produce the request.

To quantify the potential of RM, the ex-post optimum was computed. Therefore, all generated requests of an instance were given to a solver calculating the ex-post optimum by solving a relaxed knapsack problem as described in Spengler, Rehkopf, and Volling (2007). According to the sales department, in times of full use of capacity, the incoming demand exceeds the capacity by about $5 \%$ to $20 \%$ depending on the specific period. Therefore, the focus of the studies was on demand/capacity ratios of 1.00 to 1.20.

The necessary parameters for the simulation were derived from an extensive data analysis and vali- dated in discussions with experts. Generally, demand/capacity ratios are difficult to be generated in network environments. In the simulation, the available capacities of the production units were standardized to average capacity required to produce a demand volume at which the production network is considered as running "at full capacity". This demand volume was divided by the mean volume of the requests to calculate the average number of requests that needs to be generated to provide a $100 \%$ capacity load across the production network. Based on this, the resource capacities were computed by an ample number of simulation runs and are measured in hours.

To create the particular demand/capacity ratios the number of requests to be generated was multiplied by an adjustment factor, while keeping the capacities of the production units fixed. For instance, to simulate a scenario in which the mean demand exceeds available capacity by $10 \%$, the number of requests was multiplied by an adjustment factor of 1.1. Thus, these ratios quantify the mean excess of demand compared to capacity. Based on this data, 1,000 simulation runs for each demand/capacity ratio were conducted. The results are shown in Figure 8 , revealing a potential of up to $19 \%$ in overall contribution margin relative to the results of a FCFS policy.

\section{Figure 8: Ex-post analysis}

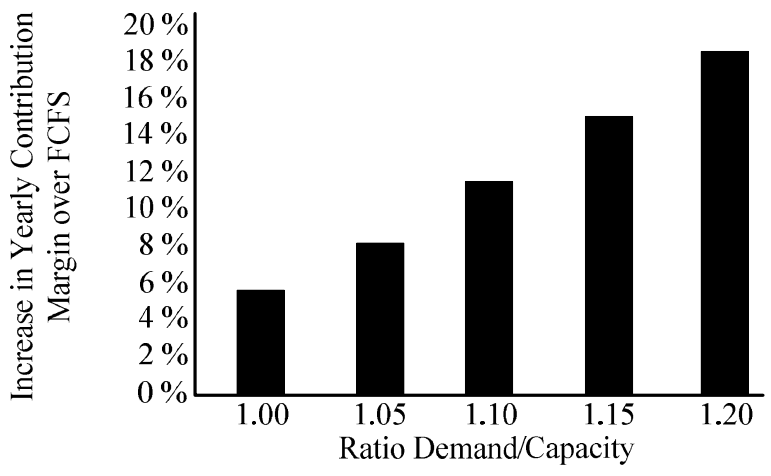

Obviously, implementing additional decision support in order to fully estimate the economical effects of accepting or rejecting an incoming request promises great potential. Using contribution margin per $\mathrm{kg}$ as a simple reference might be misleading in bottleneck situations, since it does not include the resulting capacity consumption of the request (see Figure 7). Even if the capacity consumption is included in the decision-making process, the prob- 
lem's complexity is increased if multiple potential bottlenecks need to be considered. The reductions in expected future contribution from these capacity constraints resulting from accepting a request define the opportunity costs (associated with these constraints). Therefore, to fully estimate the profitability of an incoming request, the associated opportunity costs need to be calculated based on the resulting capacity consumption, the expected requests, and the resulting value of the capacity consumed in the production network.

\section{Developing a Bid Price Control}

As described in the previous sections, decisions made by the sales agent about whether to accept a customer request or not, might have a significant effect on the overall contribution margin of the company. Generally speaking, the objective of implementing capacity control is to determine how to allocate the capacity of a given and limited resource to dynamically arriving requests, in order to maximize the profit.

In steel manufacturing, capacity control can be used for an extended decision support for the sales department, when deciding whether to accept or decline a request. Capacity control, in settings with only one resource, tries to allocate capacity to different classes of customer orders, whereas network capacity control describes a capacity allocation problem, when customers require a bundle of resources. In general, problems of network capacity control are of greater complexity since the order acceptance decision not only influences the utilization of one resource, but has influence on the usage of several other resources as well.

In this context, Talluri and van Ryzin (1998) point out that the usage of bid prices is an increasingly popular method for controlling the sale of inventory, e.g., seats on a flight or capacity in a production network. In a network bid price control the value of each resource's capacity is calculated depicting a threshold value (or bid price). Hereby, the value of one capacity unit is quantified by its resourceoriented opportunity cost, which is the expected loss in future contribution margin from using the capacity now instead of reserving it for future requests. A request (representing a specific path through a network) therefore is only accepted if the contribution margin exceeds the product oriented opportunity costs. If bid price control is applied, the opportunity costs are approximated by the sum over the bid prices multiplied by the capacity consumption on the specific resource along the path.

Figure 9 illustrates the calculation scheme of the threshold value. If a customer approaches ThyssenKrupp VDM with a quotation request, the threshold for the contribution margin for the requested product is calculated in the following manner. Using a bid price to approximate the value of the resource's capacity, the bid prices of each resource are multiplied with the request's specific capacity consumption and summed up for all resources. This results in a threshold, specific for the forecasted demand scenario and particular request. This threshold is the key information provided by the bid price control for the sales agent resulting in additional decision support for the profitability check as described in the iterative price finding process in Figure 5 .

In the example, the three resources are valued with bid prices of $5000 € / \mathrm{h}, 1000 € / \mathrm{h}$, and $750 € / \mathrm{h}$ and when multiplied with the request-specific capacity consumption (derived from the existing work plan of the product) result in a threshold of $10 € / \mathrm{kg}$. Having this threshold at hand is an additional decision support for the sales agent during price negotiations with the customers, instructing the sales agent not to quote a product price of less than 10 $€ / \mathrm{kg}$ contribution margin.

Using a more general description, let the network consist of $I$ resources and $J$ products being offered.

\section{Figure 9: Calculation of the threshold value in a production network}

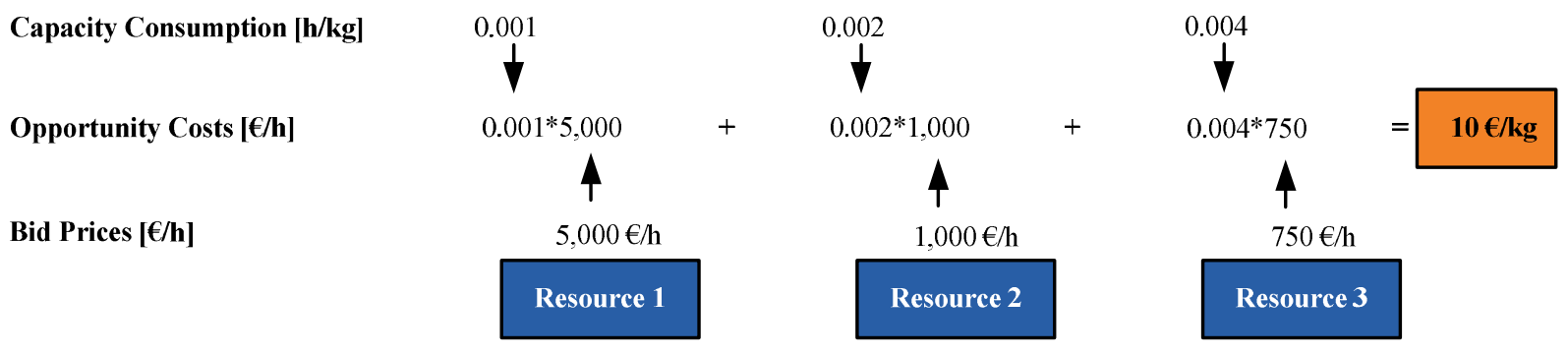


If the resource $i \in I$ is used by product $j \in J$, let $a_{i j}$ be equal to the amount of the product's demand of the resource and zero otherwise. Let the capacity consumption matrix be $\boldsymbol{A}=\left[a_{i j}\right]$ and $\mathrm{cm}_{j}$ the contribution margin of request $j$. The vector ctp indicates the remaining capacity for each resource. Furthermore, $V(c t p)$ denotes the maximum expected total contribution margin, given the remaining capacity ctp. Let $\pi_{i}$ be the bid price for resource $i$. Thus, a request $j$ is accepted, only if

$$
c m_{j} \geq \sum_{i=1}^{I} \boldsymbol{\pi}_{i}(\boldsymbol{c t p}) \cdot a_{i j} .
$$

Obviously, two factors influence the value of the contribution margin threshold: the request-specific capacity consumption and the value of the resourcespecific bid prices. The capacity consumption of the request can be derived from the available work plans, whereas the bid prices are computed in two steps. First, an optimization problem is solved to determine the optimal capacity allocation. The objective is to maximize the expected total revenue. The informational basis is given by the available capacity and the demand forecast. In a second step, the shadow prices of the capacity constraints are used as bid prices for the resources.

Typically, in the above-described environment, a multi-period capacity allocation model is chosen, accounting for the varying product-specific lead times. Nevertheless, the request-specific capacity consumptions on the production network are very small compared to the considered length of production periods. Thus, without loss of generality, it is a valid assumption that all requests with the same period of delivery are manufactured within the same period. Modarres and Sharifyazdi (2009) conclude that in this context, the problem can be formulated as a single-period model. Accordingly, a static, single-period model is used. Each period consists of one week.

The deterministic linear programming model (DLP), first introduced into the RM context by Smith and Penn (1988) and Williamson (1992), is a very widespread optimization model to calculate bid prices. For instance, let $\mathrm{cm}_{j}$ represent the historical average contribution margin that was realized from one unit of product $j$ and $\mathbf{c m}$ its vector. Let $D_{j}$ represent the forecasted total demand for product $j$ and $\boldsymbol{D}$ the demand vector. The decision va- riables $\boldsymbol{x}=\left\{x_{1}, \ldots, x_{J}\right\}$ denote the production quantity for product $j$.

Using the above-described notation, the bid price control can be derived from the optimal solution of the following deterministic linear programming model:

$$
\begin{aligned}
& V^{D L P}(\boldsymbol{c t p})=\max \boldsymbol{c m}^{T} \boldsymbol{x} \\
& \text { s.t. } \boldsymbol{A} \boldsymbol{x} \leq \boldsymbol{c t p} \\
& 0 \leq \boldsymbol{x} \leq E[\boldsymbol{D}]
\end{aligned}
$$

Using a DLP, the assumption is made in equation (4) that the demand is deterministic and equal to the mean demand depicted by $\mathrm{E}[\mathbf{D}]$ as the vector of expected demand for all $J$ products. Since the stochastic demand information is reduced to expected demand, the approximation of the bid prices is expected to capture uncertainty in an insufficient manner. This is especially true, if the DLP is applied to the context of m-t-o manufacturing with a high variance in order-specific capacity consumptions. Further, practical examples for the difficulty of applying a deterministic model in m-t-o steel manufacturing are given in the following section.

The DLP's popularity in practical applications results from its efficient computational solving and that even though it is simple, it has a relatively good performance rating (compare the results of Metters, Queenan, Ferguson, Harrison, Higbie, Ward, Barfield, Farley, Kuyumcu, and Duggasani 2008). This is the case when frequent re-optimization is undertaken (Talluri and van Ryzin 2004).

A relatively simple modification of the model, where the stochastic demand is modeled explicitly, leads to the concept of randomized linear programming (RLP) as proposed by Smith and Penn (1988) and later investigated by Talluri and van Ryzin (1999). Solving the model for $\mathrm{k}$ simulated independent scenarios of the demand vector $\mathbf{D}$ results in $\mathrm{k}$ bid prices $\boldsymbol{\pi}\left(\boldsymbol{c t} \boldsymbol{p}, \boldsymbol{D}^{(y)}\right)$, with $y \in\{0, \ldots, k\}$. The remaining capacity ctp is assumed to be constant in every simulated scenario. The bid price vector $\boldsymbol{\pi}^{\mathrm{RLP}}$ is finally received as mean of the bid prices of the different scenarios:

$$
\boldsymbol{\pi}^{R L P}=\frac{1}{k} \sum_{y=1}^{k} \boldsymbol{\pi}\left(\boldsymbol{c t p}, \boldsymbol{D}^{(y)}\right)
$$


Figure 10: Approaches of DLP (left) and RLP (right) to consider demand fluctuations

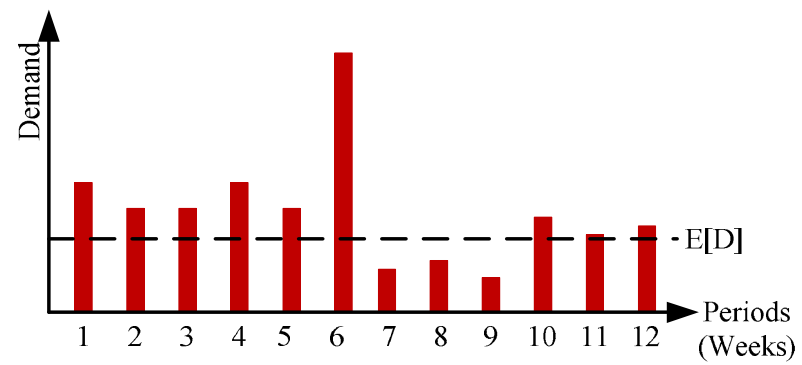

Although not yet popular in the research community or industry (Topaloglu 2009), this approach captures the situation at ThyssenKrupp VDM in a much better way than the simplifying assumptions of the DLP as will be explained in the following.

First of all, Topaloglu (2009) gives a mathematical proof of the asymptotical optimality of the RLP and investigates the number of samples needed for the case of an airline network. Talluri and van Ryzin (1999) also conclude that in their investigated problem the RLP is barely subject to degeneracy.

Second, the necessity of an approach based on multiple samples becomes obvious, when explaining the RLP approach in the context of the specific order characteristics at ThyssenKrupp VDM. In Figure 10 the historic demand for a specific product is depicted for twelve periods. On the left-hand side, the mean value of the demand $E[D]$ is shown by the dotted line, representing the input for the DLP. On the right-hand side, $\mathrm{D}^{(1)}$ to $\mathrm{D}^{(8)}$ represent eight demand scenarios simulated by the RLP.

In a demand environment of high volatility as experienced by ThyssenKrupp VDM the RLP is more advantageous and robust regarding forecasting errors, as will be elaborated further in the results

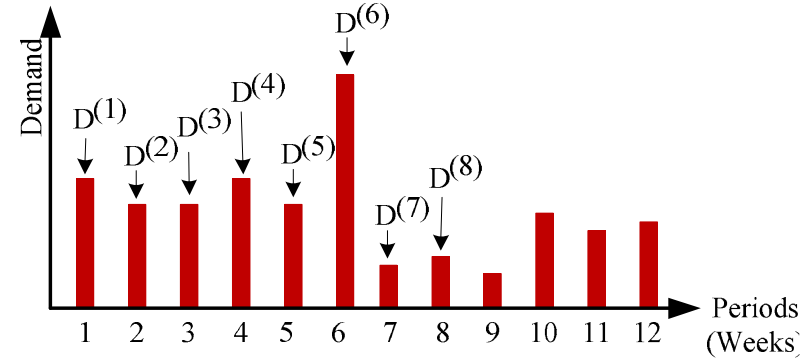

section. Specifically, by increasing the number $\mathrm{k}$ of independent demand scenarios, the quality and complexity of the calculation can be varied allowing to better capture demand distributions in practice. Capturing a demand distribution in an m-t-o setting is challenging due to two reasons: In contrast to the airline industry, not only the customer's demand (measured in tons per alloy) is of interest, but also the resulting capacity consumption on different resources. For this reason, the RLP offers the opportunity to consider a variety of scenarios with different compositions of demand and associated capacity consumptions.

Figure 11 exemplifies the fluctuation in capacity consumption for 500 demand scenarios for the annealing (left) and the dry grinding (right). Due to reasons of confidentiality, instead of publishing real data we chose to refer to simulation results inheriting the characteristics of the actual data. Observe that although the generated demand volume was the same for each scenario, the stochastic composition of the demand with regard to type of alloy and different specifications results in fluctuating capacity consumptions. Interestingly, depending on the demand scenario, the capacity load of the annealing

Figure 11: Ratio required capacity/available capacity of 500 demand scenarios at maximum producible volume for annealing (left) and dry grinding (right)
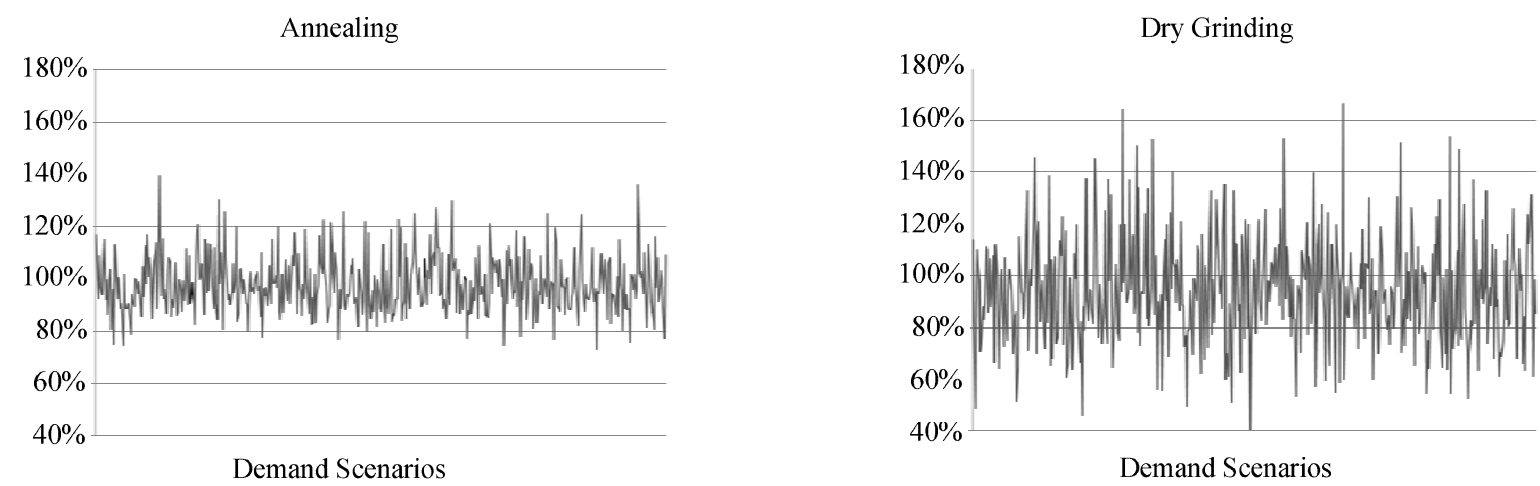
varies between $75 \%$ and $140 \%$ whereas the capacity load varies between $40 \%$ and $170 \%$ for the dry grinding. This is due to the nature of the request flow at ThyssenKrupp VDM as depicted in Figure 4. The vast majority of incoming requests consumes capacity on the annealing, blasting and straightening, whereas the capacity consumption of the dry grinding depends on the request's specifications and can be considered as an "option" which can be booked in addition to capacities on the main request flow.

To further illustrate the fluctuation in capacity loads, the box plots of the simulation results for all five potential bottlenecks are illustrated in Figure 12. Observe that in 500 demand scenarios the annealing shows the highest median capacity load, turning it into a bottleneck in the majority of scenarios. Blasting, straightening and spray pickling have about the same low load, making them a bottleneck only in a small percentage of demand scenarios. The dry grinding also has a high median capacity load accompanied with the highest interquartile range and several outliers. Thus, it is to be investigated whether using a DLP with the assumption of a deterministic demand scenario captures the demand uncertainty faced by ThyssenKrupp VDM as well as running $\mathrm{k}$ independent demand scenarios with a RLP. The stochastic nature of demand faced by ThyssenKrupp VDM expresses itself in the uncertainty of the volume ordered (measured in tons), the value of the order (measured in EUR $/ \mathrm{kg}$ ), and its associated capacity consumption (measured in hours). As shown above, an accurate forecast with regard to volume ordered might still lead to a variety of different scenarios of capacity consumption in the production network.

Figure 12: Capacity loads of potential bottlenecks at maximum producible volume

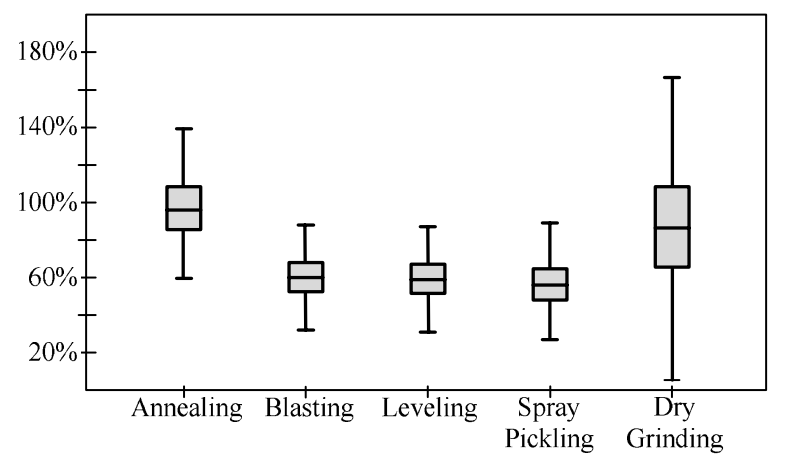

\section{Obstacles Encountered in Forecasting}

Having an accurate forecast is an essential element of any RM system (Weatherford and Kimes 2003). If the forecast of the amount and the value of the expected orders exceed the real amount of incoming requests, the computed bid prices and the resulting contribution margin threshold will be too high, resulting in the rejection of customer requests, which should have been accepted. On the other hand, if the forecast is too low, the bid prices and the resulting threshold will not be restrictive enough to ensure the selection of requests maximizing the overall contribution margin. Or as DeMiguel and Mishra (2008: 1) state, „The performance of a bid price policy depends crucially on the quality of the calculated bid prices".

In general, RM relies on accurate forecasts of capacity, demand, and price. At ThyssenKrupp VDM, the capacity can be assumed as given, leaving demand and price to be forecasted, where demand is generally considered the most challenging one (Zaki 2000). This is especially true when forecasting in an $\mathrm{m}$-t-o environment. When trying to implement RM in practice, one encounters a certain amount of misunderstanding about RM forecasting among nontechnical analysts and managers being accustomed to think about forecasting as generating point estimates. Similar experience is reported by Talluri and van Ryzin (2004).

\section{Figure 13: Demand fluctuation for a single alloy}

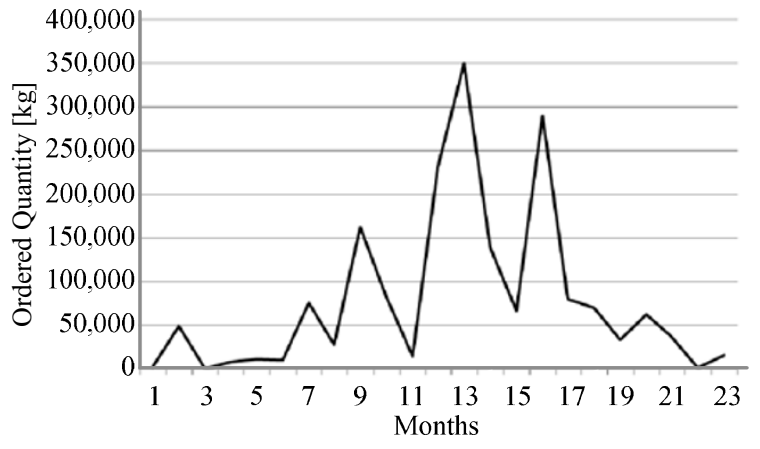

Nevertheless, at ThyssenKrupp VDM the heterogeneity of customer orders makes an accurate forecast very difficult. For instance, during the period of two fiscal years, each order specification was produced only 2.8 times on average, which indicates a high variety. Figure 13 gives an example of the typical high fluctuation in demand for a specific alloy, 
varying between $\mathrm{o}$ and 350 tons per month. Note that this is already the aggregated demand of an alloy, comprising many different order specifications.

\section{$7 \quad$ Resulting Benefits}

To quantify the benefits of implementing RM at ThyssenKrupp VDM, an abstract model of the order acceptance process was simulated. Simulation was used to incorporate the characteristics of the realworld process in the best possible way.

In the simulation, a production network consisting of five production units (annealing, blasting, leveling, spray pickling, dry grinding) was modeled. This does not describe the production network of the sheet finishing section completely. However, all other units do not represent bottlenecks and can thus be excluded from the analysis.

In order to generate input information for RM, historic order information obtained from an extensive database were used. For the conducted studies, data of two fiscal years was available. The database contained general information (e.g., type of customer, date of order, date of delivery), technical details (e.g., alloy, cold or hot-rolled, geometric dimensions), information about production (e.g., start of production, production route, capacity consumption, work plans, rework), and commercial information (e.g., price, costs for sales, transport, material, and production) for each order. In addition, information about the production network including the available capacity was used.

The demand generation in the simulation is based on using historical orders characterized by specific volume, capacity requirements, and contribution margin. Sampling from historic data ensures that all correlations are included. The database, as described in Table 1, consisted of 7,709 historical orders produced in two fiscal years. It also included orders with a negative contribution margin as it consisted of actual instead of planning data. Interestingly, whereas the annealing, blasting, leveling, and pickling units were occupied by at least $90 \%$ of the orders, only $37.23 \%$ occupied the grinding unit, respectively. Nevertheless, all five units are considered as potential bottlenecks as the grinding unit, for instance, reports the highest mean capacity consumption of the orders and the highest coefficient of variation which explains the high fluctuation depicted in Figure 11.

The structure of the simulation model is given in Figure 14. It comprises four components: demand generation, shadow price determination, order acceptance simulation, and statistics collection. They are described in detail in the following.

The challenge of demand generation is the modeling of a stochastic process which replicates the characteristics of the regarded industry setting. The information which is available when applying RM comprises data/forecasts on the number of incoming customer requests and requested lead times. Hereby, the lead time is defined as the difference between completion time and the time a request arrives. Necessary to evaluate capacity control policies, however, is information on the requests' capacity requirements in their period of production. To generate this information, the following approach was chosen:

Table 1: Statistical description of database available for simulation

\begin{tabular}{lclc}
\hline Number of orders & 7,709 & Number of fiscal years & 2 \\
\hline Contribution margin $/ \mathrm{kg}(\mathrm{cv})$ & 0.57 & Occupied production units by order $(\mu / \mathrm{cv})$ & $3.94 / 0.16$ \\
\hline Volume of average order $(\mathrm{cv})$ & 1.05 & Number of same orders $(\mu)$ & 2.8 \\
\hline Number of different alloys & 51 & & \\
\hline
\end{tabular}

Annealing Blasting Leveling Pickling Grinding

\begin{tabular}{|c|c|c|c|c|c|}
\hline$\%$ of orders consuming capacity & $90.02 \%$ & $93.70 \%$ & $93.91 \%$ & $89.86 \%$ & $37.23 \%$ \\
\hline Capacity consumption of order $(\mu / \mathrm{cv})$ & $0.47 \mathrm{~h} / 1.42$ & $0.35 \mathrm{~h} / 1.21$ & $0.35 \mathrm{~h} / 1.20$ & $0.40 h / 1.26$ & $0.47 \mathrm{~h} / 3.37$ \\
\hline Consumption of total capacity $(\mu)$ & $<<0.5 \%$ & $<<0.5 \%$ & $<<0.5 \%$ & $<<0.5 \%$ & $<<0.5 \%$ \\
\hline Contribution margin/h of production unit (cv) & 0.958 & 1.071 & 1.057 & 0.975 & 0.884 \\
\hline
\end{tabular}

$\mu$ : mean $c v$ : coefficient of variation 


\section{Figure 14: Structure of the simulation model}

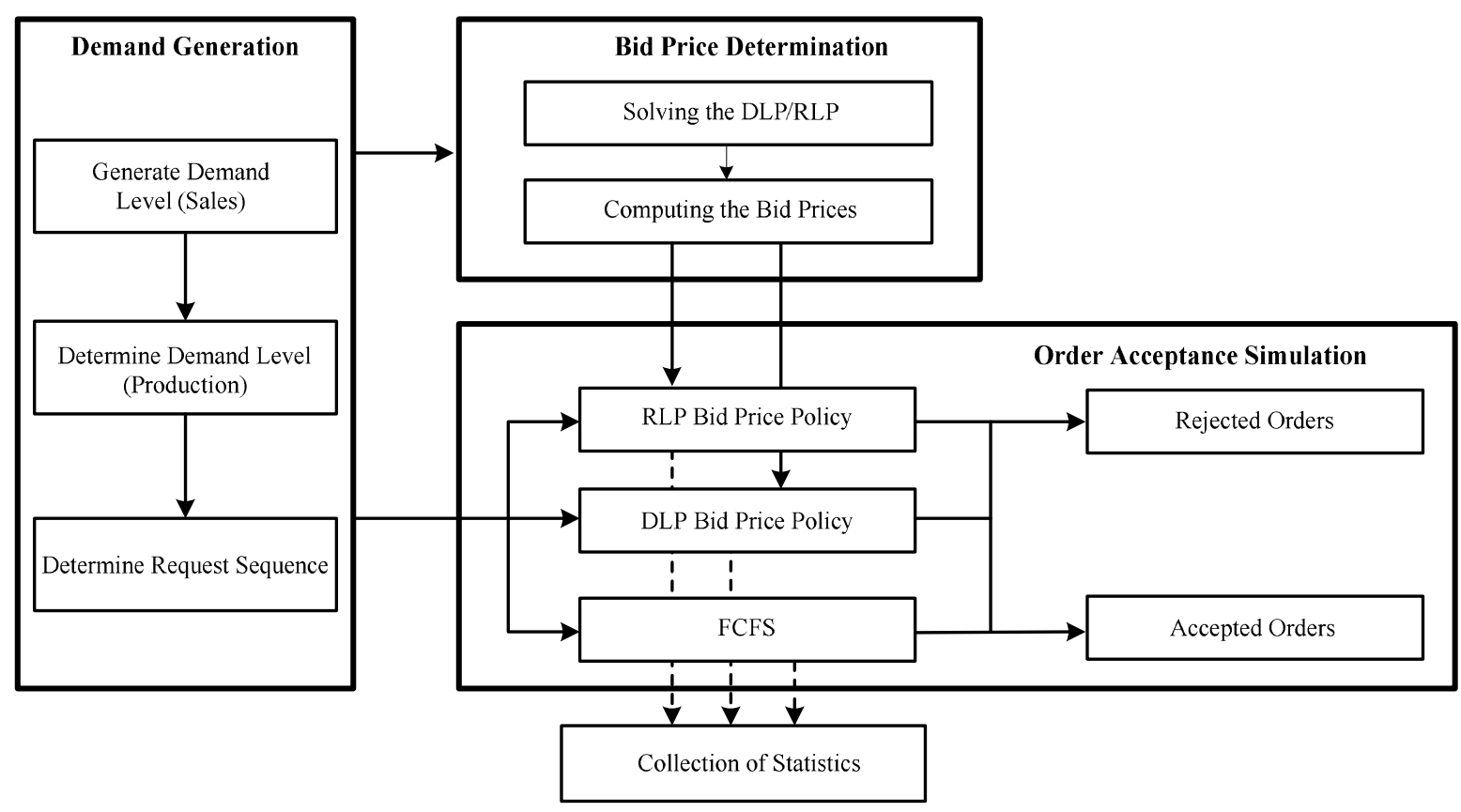

1. In a first step the demand level was generated in terms of the incoming requests of each sales period, being one week. Due to the large number of requests, the number of requests can be regarded as a suitable indicator for the demand level. In accordance with the literature, a Poisson distribution was used and fitted to the actual data. Different ratios of demand/capacity were obtained by adjusting the Poisson parameter.

2. Based on the number of requests in each sales period, information on the requested lead times was incorporated to transfer the sales data into production data. More specifically, for each request a product-group-specific lead time was drawn from a normal distribution, with parameters ranging from $\mu=17$ weeks and $\sigma=4.2$ weeks to $\mu=26$ weeks and $\sigma=10.7$ weeks. The request was then allocated to the corresponding period of production.

3. In a third step, the database of historical orders was used to attribute each request with specific properties. A uniform distribution was applied to randomly draw request characteristics from the database. As a result a representative sequence of requests was created for each period of production. To avoid any bias induced by the model initialization, the demand information of the first 48 periods was excluded from further analysis.

The bid prices are determined using input information from the demand generation module. In case of the RLP, requests for 150 instances (consisting of one week of orders) were generated, which is an ample number with respect to the convergence of the bid price results. For each instance a linear program was solved to calculate the shadow prices. To derive the bid prices to be applied in the order acceptance process, the mean of the 150 instances was computed according to (5).

For the DLP a slightly modified demand generation procedure was applied. Having completed step 2, the mean number of requests in each period was computed. This number was used to generate a single sequence of requests as elaborated in step 3.

The order acceptance simulation is based on request sequences for 5,000 periods computed by the demand generation module. For each period the order acceptance process was simulated separately, yielding 5,000 single-period problems. Plant Simulation 8.1 by Tecnomatix was used for discrete event simulation. Three different policies were analyzed: the FCFS policy, the DLP bid price policy, and the RLP bid price policy.

The order acceptance policies only accept requests if 
the remaining production capacity is sufficient to produce the request (CTP check in Figure 5). Whereas the FCFS policy accepts a request if the request's contribution margin is positive, the DLP and RLP policy only accept requests if the requests' contribution margin exceeds the threshold calculated by the bid price control according to Figure 9. The available production capacity is considered as fixed and exogenous for the simulation defined as described in section 4. Common random numbers are applied throughout all policies as variance reduction technique. The fourth component of the simulation is the collection of statistics and results as described in Figure 14.

To point out the advantage of RM in different demand scenarios, different ratios of demand to capacity were defined as described in section 4 and investigated. The simulation results of using a bid price control in the order acceptance process are promising. The results in yearly contribution margin relative to the results of a FCFS order selection policy are shown in Figure 15 (left side). Observe that depending on the demand/capacity ratio, an average increase of up to $13 \%$ in overall contribution margin is to be expected using the RLP exceeding the DLP in each demand/capacity ratio. The right side depicts the fluctuating gain of implementing a RLP bid price control compared to a FCFS policy. As expected, the gain increases with the overloading of capacity, whereas no negative gains could be observed, proving the benefits of the capacity control in every possible demand scenario.

At the same time, while increasing the yearly average contribution margin, ThyssenKrupp VDM is able to increase the produced quantity by up to $8 \%$ depending on the demand/capacity ratio. This is mainly due to the incorporation of the contribution margin per capacity consumption in the order acceptance process.

One of the major questions of the sales department was the question about rejected customer requests. How many price negotiations with customers would be affected by the RM system and will there be more rejections of customer requests because of a high threshold for the contribution margin to be quoted? The exact opposite, in fact, is true. Taking a closer look at the reason why requests are rejected at both order acceptance policies, the consequences of not implementing forecasting into the order acceptance process is obvious. Exemplifying a ratio of demand to capacity of 1.2, the left part of Figure 16 illustrates that fewer requests are rejected with a RLP bid price control in absolute and relative numbers. Even if a request is rejected by the RLP bid price control, it is largely due to customer's willingness to pay rather than a lack of available capacity. On the other hand, maintaining the current FCFS policy will lead to more rejected requests and mainly due to the lack of available capacity (note that in our simulation run, it was possible for the FCFS policy to reject requests due to low contribution margin since the database also contained orders with a low negative contribu-

\section{Figure 15: Gain in contribution margin of DLP as well as RLP (left) and fluctuation of RLP-} gain (right)

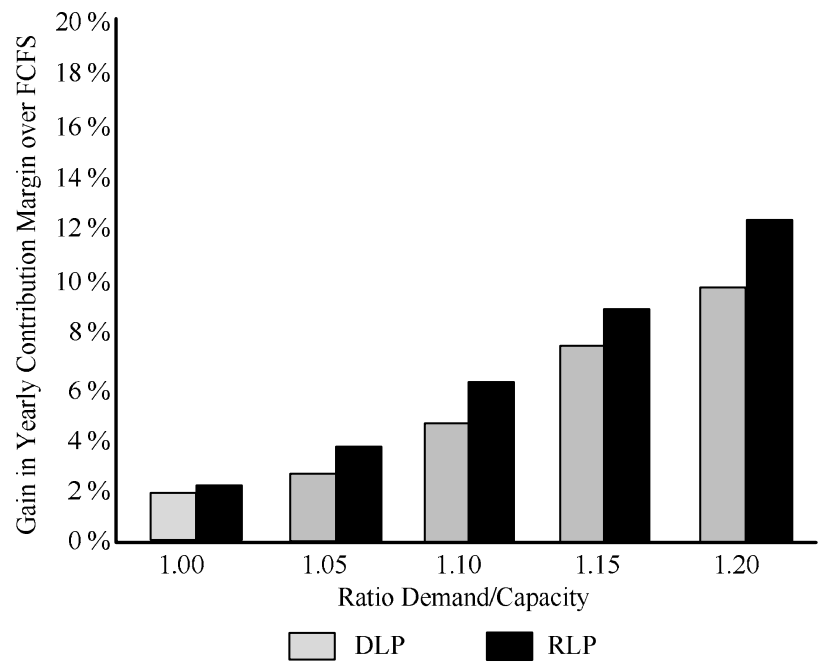

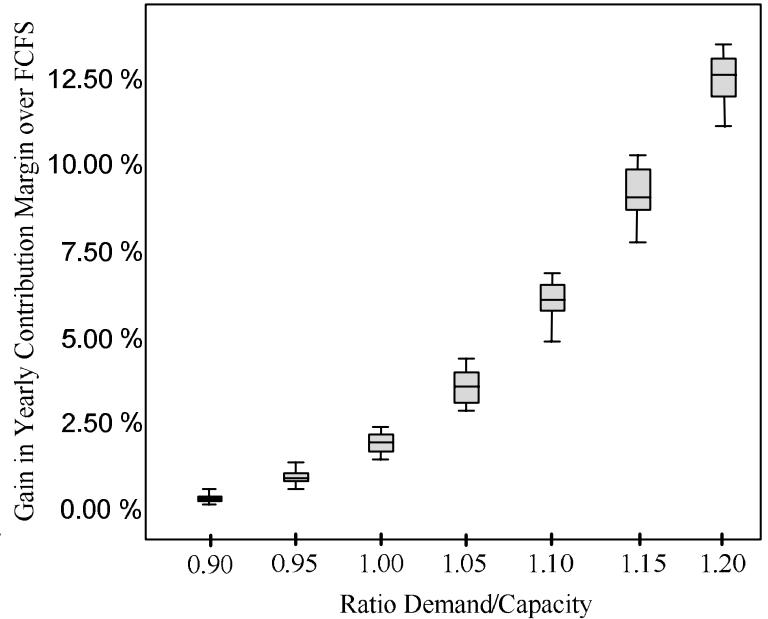


Figure 16: Rejected requests (left) and accepted orders (right) of different policies

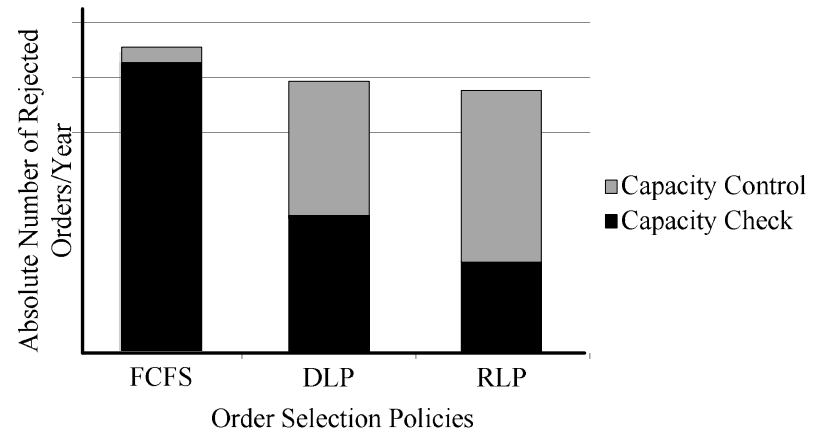

tion margin). Obviously, the lower number of customer requests rejected by the bid price control results in a higher acceptance rate. The right part of Figure 16 illustrates the gap between RLP, DLP and FCFS with an increasing ratio demand to capacity. Figure 17 displays the development of the resulting capacity load exemplified for the annealing unit. The RLP bid price control leads to a lower capacity load in every demand scenario, which is not to be interpreted as a too restrictive order acceptance policy. Much rather, combined with the above results it indicates the method's good capability to select profitable requests leading to an efficient capacity utilization. The depicted capacity load of less than 100 percent results from averaging the results of several simulation runs.

\section{Figure 17: Capacity load of the annealing furnace}

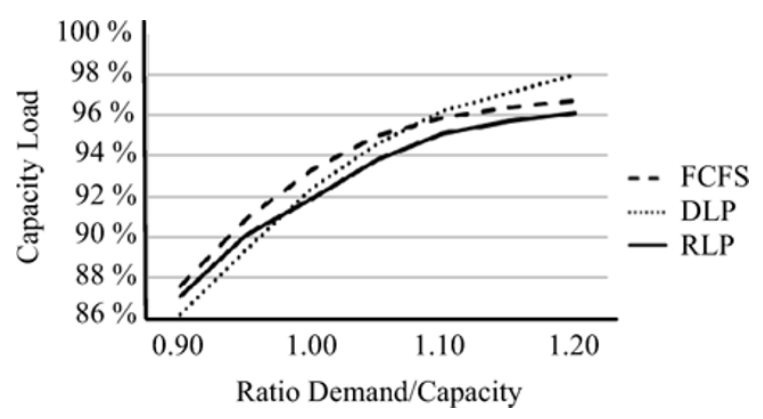

Interestingly, the combined interpretation of the results of Figure 16 and Figure 17 indicates no direct correlation of the relative numbers of accepted requests and the resulting capacity consumption. This is mainly due to the network environment and the bid price control's tendency to choose requests with

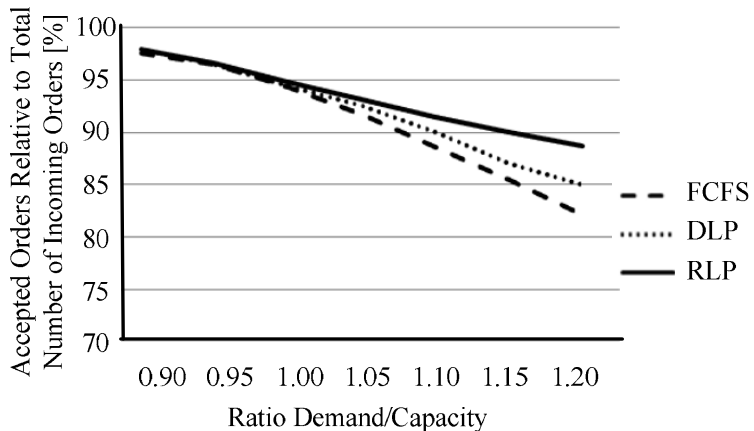

a high contribution margin and low capacity consumption.

Figure 18 contrasts the results of the ex-postanalysis and the simulation results of the DLP and the RLP bid price controls regarding the overall contribution margin. Despite the impressive results of the RLP bid price control, the m-t-o production environment still offers room for further improvements.

\section{Figure 18: Comparison of the results}

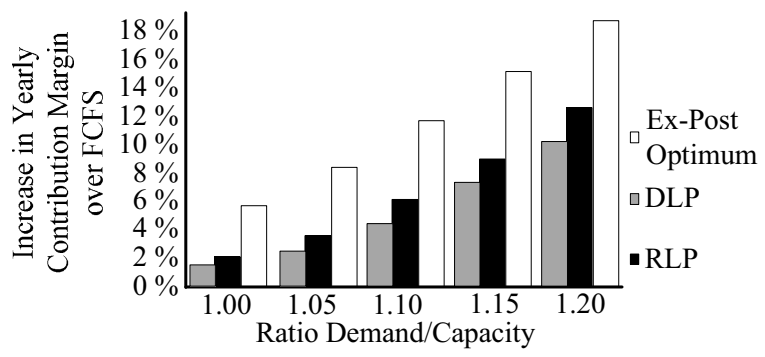

\section{Conclusions}

Our presented approach of implementing linear programming for an order selection problem in steel manufacturing is a first attempt at introducing RM techniques. Several conclusions can be drawn from the RM project at ThyssenKrupp VDM. Generally speaking, the production environment of m-t-o steel manufacturing meets the necessary requirements for an effective usage of RM instruments. Further, the RLP bid price control

(i) allows for an adequate consideration of the request's capacity requirements in the order acceptance process,

(ii) results in gains in contribution margin and quantity of up to $13 \%$ and $8 \%$, respectively. Although these numbers represent the mean values, 
the benefits of RM in every possible demand scenario can be shown,

(iii) leads to a lower number of rejected customer requests, resulting in a higher acceptance rate,

(iv) leads to a lower capacity load compared to a FCFS policy in every demand scenario.

Although the use of RLP bid prices leads to impressive results and skims a large portion of the potential benefits, there is still room for improvements both in applied methods and their application.

Further research and development in the methods of RM will focus mainly on two areas: First, research needs to be conducted in the area of updating forecast and available capacity, as well as the resulting re-optimization. To the best of our knowledge, no systematic framework for updating and re-optimizing in an m-t-o network setting currently exists. Secondly, recent approaches of dynamic bid prices based on simulation-based optimization show great potential for implementation at ThyssenKrupp VDM. Both research directions will be tackled in the ongoing project.

\section{Acknowledgements}

The authors wish to express their thanks to the department editor and the two anonymous referees of this paper for their valuable comments and suggestions that helped to improve this paper.

In addition, the authors would like to thank the employees of ThyssenKrupp VDM GmbH for their cooperation and helpful suggestions throughout the research project.

\section{References}

Balakrishnan, Nagraj, Sri V. Sridharan, and J. Wayne Patterson (1996): Rationing Capacity Between Two Product Classes, Decision Sciences, 27 (2): 185-214.

Barut, Mehmet and Sri V. Sridharan (2005): Revenue Management in Order-Driven Production Systems, Decision Sciences, 36 (2): $287-316$.

Chiang, Wen-Chyuan, Jason C.H. Chen, and Xiaojing Xu (2007): An Overview of Research on Revenue Management: Current Issues and Future Research, International Journal of Revenue Management, 1 (1): 97-128.

Cross, Robert G. (1997): Revenue Management: Hard-core Tactics for Market Domination, Broadway Books: New York.

Defregger, Florian and Heinrich Kuhn (2007): Revenue Management for a Make-To-Order Company with Limited Inventory Capacity, OR Spectrum, 29 (1): 137-156.

DeMiguel, Victor and Nishant Mishra (2008): What Multistage Stochastic Programming can do for Network Revenue Manage- ment, Working Paper, http://faculty.london.edu/avmiguel/DeMiguel-Mishra-Manuscript.pdf (Access date: 2010-07-28).

Denton, Brian, Diwakar Gupta, and Keith Jawahir (2003): Managing Increasing Product Variety at Integrated Steel Mills, Interfaces, 33 (2): 41-53.

Dutta, Goutam and Robert Fourer (2001): A Survey on Mathematical Programming Applications in Integrated Steel Plants, Manufacturing \& Service Operations Management, 3 (4): 387400.

Gallien, Jérémie, Yann Le Tallec, and Tor Schoenmeyr (2004): A Model for Make-To-Order Revenue Management, Working Paper, CiteSeerX.

Geraghty, M.K. and Ernest Johnson (1997): Revenue Management Saves National Car Rental, Interfaces, 27 (1): 107-127.

Gupta, Diwakar and Lei Wang (2004): Manufacturing Capacity Revenue Management, Working Paper, CiteSeerX.

Harris, Frederick H. deB. and Jonathan P. Pinder (1995): A Revenue Management Approach to Demand Management and Order Booking in Assemble-To-Order Manufacturing, Journal of Operations Management, 13 (4): 299-309.

Jalora, Anshu (2006): Order Acceptance and Scheduling at a Make-To-order System Using Revenue Management, http://repository.tamu.edu/bitstream/handle/1969.1/4421/etd-tamu-200 6B-INEN-Jalora.pdf?sequence $=1$.

Kimes, Sheryl E. (1989): Yield Management: A Tool for CapacityConstrained Service Firms, Journal of Operations Management, 8 (4): 348-363.

Kniker, Timothy S. and Mitchell H. Burman (2001): Applications of revenue management to manufacturing, in: University of the Aegean (eds.): Third Aegean International Conference on Design and Analysis of Manufacturing Systems, May 19-22, 2001, Tinos Island, Greece, Editions Ziti: Thessaloniki, 299-308.

Lin, Chin-Wen and Colin L. Moodie (1989): Hierarchical Production Planning for a Modern Steel Manufacturing System, International Journal of Production Research, 27 (4): 613-628.

Metters, Richard, Carrie Queenan, Mark Ferguson, Laura Harrison, Jon Higbie, Stan Ward, Bruce Barfield, Tammy Farley, H. Ahmet Kuyumcu, and Amar Duggasani (2008): The "Killer Application' of Revenue Management: Harrah's Cherokee Casino \& Hotel, Interfaces, 38 (3): 161-175.

Modarres, Mohammad and Mehdi Sharifyazdi (2009): Revenue Management Approach to Stochastic Capacity Allocation Problem, European Journal of Operational Research, 192 (2): 442459.

Mohanty, R.P. and R. Singh (1992): A hierarchical Production planning approach for a Steel Manufacturing System, International Journal of Operations and Production Management, 12 (5): 69-78.

Neureuther, Brian D., George G. Polak, and Nada R. Sanders (2004): A Hierarchical Production Plan for a Make-To-Order Steel Fabrication Plant, Production Planning \& Control, 15 (3): 324-335.

Patterson, J. Wayne, Nagraj Balakrishnan, and Sri V. Sridharan (1997): An Experimental Comparison of Capacity Rationing Models, International Journal of Production Research, 35 (6): 1639-1649. 
Smith, B.C. and C.W. Penn (1988): Analysis of Alternate OriginDestination Control Strategies, AGIFORS Symposium Proceedings, 28: 123-144.

Spengler, Thomas, Stefan Rehkopf, and Thomas Volling (2007): Revenue Management in Make-To-Order Manufacturing - An Application to the Iron and Steel Industry, OR Spectrum, 29 (1): 157-171.

Swann, Julie L. (1999): Flexible Pricing Policies: Introduction and a Survey of Implementation in Various Industries, Contract Report \# CR-99/04/ESL, General Motors Corporation.

Talluri, Kalyan T. and Garret J. Van Ryzin (1998): An Analysis of Bid-Price Controls for Network Revenue Management, Management Science, 44 (11): 1577-1593.

Talluri, Kalyan T. and Garret J. Van Ryzin (1999): A Randomized Linear Programming Method for Computing Network Bid Prices, Transportation Science, 33 (2): 207-216.

Talluri, Kalyan T. and Garrett J. Van Ryzin (2004): The Theory and Practice of Revenue Management, Springer: New York.

Tang, Lixin and Guoli Liu (2007): A Mathematical Programming Model and Solution for Scheduling Production Orders in Shanghai Baoshan Iron and Steel Complex, European Journal of Operational Research, 182 (3): 1453-1468.

Tang, Lixin, Jiyin Liu, Aiying Rong, and Zihou Yang (2000): A Multiple Traveling Salesman Problem Model for Hot Rolling Scheduling in Shanghai Baoshan Iron and Steel Complex, European Journal of Operational Research, 124 (2): 267-282.

ThyssenKrupp (2006): Annual Report ThyssenKrupp AG 20052006, http:// www.thyssenkrupp.com / fr / 05_06 / en / download.html (Access date: 2009-01-27).

Topaloglu, Huseyin (2009): On the Asymptotic Optimality of the Randomized Linear Program for Network Revenue Management, European Journal of Operational Research, 197 (3): 884-896.

Weatherford, Larry R. and Sheryl E. Kimes (2003): A Comparison of Forecasting Methods for Hotel Revenue Management, International Journal of Forecasting, 19 (3): 401-415.

Williamson, Elizabeth L. (1992): Airline Network Seat Inventory Control: Methodologies and Revenue Impacts, Massachusetts Institute of Technology: Boston.

Zaki, Hossam (2000): Forecasting for Airline Revenue Management, The Journal of Business Forecasting, 19 (1): 2-6.

\section{Biographies}

André Hintsches studied Industrial Engineering and Management Science (Electrical Engineering) at the Technische Universität Braunschweig majoring in Production Management, Controlling and Mobile Communications. Since 2007 he has worked as a research assistant at the Institute of Automotive Management and Industrial Production of Prof. Dr. Spengler. His field of research is the application of Revenue Management to the manufacturing industry with consideration of uncertainties.

Thomas Spengler is Professor of Production and Logistics Management and Director of the Institute of Automotive Management and Industrial Production at the Technische Universität Braunschweig. As well as Revenue Management in make-to-order manufacturing his research interests include the development and implementation of techno-economic models for decision support. He has researched and consulted with a wide range of industries including iron and steel, automotive, and consumer goods. He has published widely in the field of Production and Logistics Management.

Thomas Volling studied Industrial Engineering and Management Science at the Technische Universität Braunschweig and the University of Rhode Island. He obtained his $\mathrm{PhD}$ in 2008 and holds the position of an Assistant Professor at the Institute of Automotive Management and Industrial Production. His area of research is make-to-order order fulfillment systems. Further interests include the development of quantitative and qualitative operational templates.

Kai Wittek studied Industrial Engineering and Management Science (Mechanical Engineering) at the Technische Universität Braunschweig and further holds a Master's degree in Industrial Engineering from the Georgia Institute of Technology. He currently works as a research assistant at the Institute of Automotive Management and Industrial Production of Prof. Dr. Spengler. His research interests are Revenue Management topics in make-toorder industries, with a special interest in managing stochastic demand.

Gerald Priegnitz studied Industrial Engineering at the Technische Universität Darmstadt. Since 1993 he has worked in different positions for various ThyssenKrupp companies. His career started in the area of Controlling. Meanwhile he works as CFO for ThyssenKrupp VDM. Since the tools for production controlling are well established, he committed himself to fine-tuning sales controlling methods. Revenue Management is an important part of that. 